\title{
The Effects of the Context-Dependent Codon Usage Bias on the Structure of the nsp1 $\alpha$ of Porcine Reproductive and Respiratory Syndrome Virus
}

\author{
Yao-zhong Ding, ${ }^{1,2}$ Ya-nan You, ${ }^{1}$ Dong-jie Sun, ${ }^{1}$ Hao-tai Chen, ${ }^{1,2}$ Yong-lu Wang, ${ }^{1,2}$ \\ Hui-yun Chang, ${ }^{1,2}$ Li Pan, ${ }^{1,2}$ Yu-zhen Fang, ${ }^{1,2}$ Zhong-wang Zhang, ${ }^{1,2}$ Peng Zhou, ${ }^{1,2}$ \\ Jian-liang Lv, ${ }^{1,2}$ Xin-sheng Liu, ${ }^{1,2}$ Jun-jun Shao, ${ }^{1,2}$ Fu-rong Zhao, ${ }^{1,2}$ Tong Lin, ${ }^{1,2}$ \\ Laszlo Stipkovits, ${ }^{3}$ Zygmunt Pejsak, ${ }^{4}$ Yong-guang Zhang, ${ }^{1,2}$ and Jie Zhang ${ }^{1,2}$ \\ ${ }^{1}$ State Key Laboratory of Veterinary Etiological Biology, National Foot-and-Mouth Disease Reference Laboratory, \\ Lanzhou Veterinary Research Institute, Chinese Academy of Agricultural Sciences, Lanzhou, Gansu 730046, China \\ ${ }^{2}$ Jiangsu Co-Innovation Center for Prevention and Control of Important Animal Infectious Diseases and Zoonoses, \\ Yangzhou, Jiangsu 225009, China \\ ${ }^{3}$ RT-Europe Research Center Ltd., Budapest, Hungary \\ ${ }^{4}$ Department of Swine Diseases, National Veterinary Research Institute, 57 Partyzantow, 24-100 Puławy, Poland
}

Correspondence should be addressed to Yong-guang Zhang; zhangyongguang@caas.cn and Jie Zhang; zhangjie03@caas.cn

Received 18 March 2014; Revised 5 June 2014; Accepted 19 June 2014; Published 3 August 2014

Academic Editor: Hongwei Wang

Copyright (c) 2014 Yao-zhong Ding et al. This is an open access article distributed under the Creative Commons Attribution License, which permits unrestricted use, distribution, and reproduction in any medium, provided the original work is properly cited.

\begin{abstract}
The information about the crystal structure of porcine reproductive and respiratory syndrome virus (PRRSV) leader protease nspl $\alpha$ is available to analyze the roles of tRNA abundance of pigs and codon usage of the $n s p l \alpha$ gene in the formation of this protease. The effects of tRNA abundance of the pigs and the synonymous codon usage and the context-dependent codon bias (CDCB) of the $n s p l \alpha$ on shaping the specific folding units ( $\alpha$-helix, $\beta$-strand, and the coil) in the nspl $\alpha$ were analyzed based on the structural information about this protease from protein data bank (PDB: 3IFU) and the $n s p 1 \alpha$ of the 191 PRRSV strains. By mapping the overall tRNA abundance along the $n s p 1 \alpha$, we found that there is no link between the fluctuation of the overall tRNA abundance and the specific folding units in the nspl $\alpha$, and the low translation speed of ribosome caused by the tRNA abundance exists in the $n s p 1 \alpha$. The strong correlation between some synonymous codon usage and the specific folding units in the nspl $\alpha$ was found, and the phenomenon of CDCB exists in the specific folding units of the nspl $\alpha$. These findings provide an insight into the roles of the synonymous codon usage and CDCB in the formation of PRRSV nspl $\alpha$ structure.
\end{abstract}

\section{Introduction}

Porcine reproductive and respiratory syndrome virus (PRRSV) is an economically important pathogen of swine. The PRRSV belongs to the order Nidovirales, family Arteriviridae, genus Arterivirus [1]. The PRRSV genome contains at least 9 open reading frames, including ORFla encoding papain-like cysteine protease, ORFlb encoding RNA dependent RNA polymerase, ORFs 2-6 encoding envelop proteins, and ORF7 encoding the nucleocapsid protein $[2,3]$. PRRSV strains can be divided into two distinct serotypes, namely, the North American isolate (US) and the European isolate (EU) [4-8].

The replicative enzymes of the PRRSV are encoded in ORFla and ORF1b, which locate in the $5^{\prime}$ proximal three quarters of the viral genome. The two polyproteins encoded by ORFla and ORF1b are cleaved extensively by the nonstructural protein 4 (nsp4) deriving from ORFla, yielding a series of nonstructural proteins [9]. In particular, the nsp1 and the nsp 2 proteases release themselves from the ORFla polyprotein firstly, and the nspl can be further processed into two multifunctional proteases, namely, the nspl $\alpha$ and 
the $\mathrm{nsp} 1 \beta[10,11]$. The arterivirus nsp1 region contains a tandem of papain-like autoprotease domains (PCP $\alpha$ and $\operatorname{PCP} \beta$ ), and the arterivirus $\mathrm{PCP} \alpha$ and $\mathrm{PCP} \beta$ domains were found to be active in the reticulocyte lysates and the $E$. coli systems $[12,13]$. This biological feature might indicate that the active functions of PCP $\alpha$ and PCP $\beta$ are free from the different types of the expression systems and depend on the correct folding by themselves. As for the nspl $\alpha$, it plays an important role in regulating the accumulation of both genome- and subgenome-length minus-strand RNA and thereby fine-tuning the relative abundance of each of viral mRNAs in the infected cells $[10,14,15]$. The correct secondary structure of the nspl $\alpha$ is required for the biological functions of the protease. Based on the crystal structure of the nspl $\alpha$, it was found that this nonstructural protein has three domains, namely, the $\mathrm{N}$-terminal zinc finger (ZF) domain, the papain-like cysteine protease domain, and the carboxylterminal extension [16]. Recently, the role of the nspl $\alpha$ in impairing the host immune response has been reported [17]; however, little information about the relationship between synonymous codon usage and the secondary structure of the PRRSV nspl $\alpha$ is available to date.

The synonymous codon usage and translational speed of gene play important roles in many biological functions, like translation efficiency, genetic diversity, amino acid conservation, transfer RNA abundance, coevolution of the virus and its hosts, and context-dependent codon bias (CDCB), and so forth [18-22]. The nucleotide composition of a coding sequence (CDS) is nonrandom, and the CDS nonrandomness is influenced by the preferences in the selection of synonymous codons pairing to the same amino acid (termed as the synonymous codon usage bias SCUB). The link between SCUB and specific folding unit of protein gives us a new insight into the correct formation of the secondary structure of proteins [23-26]. It is noted that mRNA sequences generally have an additional potential to carry correct structural information in the forms of SCUB, which can be involved in a single codon or a nucleotide context of the target coding sequence $[27,28]$. As for SCUB, neighboring nucleotides flanking a codon regulate the usage of the specific codon from the synonymous family, termed as context-dependent codon bias (CDCB) [20, 29-31]. It has been reported that the most important nucleotide determining CDCB is the first nucleotide after a codon, termed as the $N_{1}$ context [32]. Although several evidences indicate the link between SCUB and the formation of the specific folding unit of viral protein, little information about the role of CDCB in the formation of the specific folding unit is reported up to date. In this study, we employed the structural information about the nspl $\alpha$ of PRRSV and several simple formulas to analyze the relationship between the CDCB of the PRRSV nspl $\alpha$ gene and the protease.

\section{Materials and Methods}

2.1. Information of PRRSV Gene and Structure of the nspla. The 191 coding sequences of PRRSV containing the $n s p 1 \alpha$ gene were downloaded from the National Center for Biotechnology Information (NCBI) (http://www.ncbi .nlm.nih.gov/Genbank/) and the accession numbers of the sequences were listed in Table S1 available online at http://dx.doi.org/10.1155/2014/765320. To investigate SCUB of the $n s p 1 \alpha$, the related genes were obtained from these 191 coding sequences by the multiple sequence alignments performed with the Clustal W (1.7) computer programs [33]. The information about the secondary structure of the PRRSV nspl $\alpha$ was obtained from protein data bank (PDB: 3IFU).

\subsection{Analysis of the Overall tRNA Abundance of Each Codon} Position along the nspla Gene. To identify the translation selection caused by the various tRNA copy numbers (reflecting tRNA abundance) of the pigs (http://gtrnadb.ucsc.edu/) at each codon position in the PRRSV nspl $\alpha$, we devised an index ( $C$ value) representing the overall tRNA abundance for a particular codon position in a target gene. Consider

$$
C=\sqrt[n]{\prod_{1}^{n}\left(\frac{W i j}{W j}\right)}
$$

where $C$ value indicates the overall tRNA abundance for a particular codon position in the target gene, $W_{i j}$ represents the tRNA copy numbers of a synonymous codon $(i)$ for the corresponding amino acid $(j), W_{j}$ represents the optimal tRNA copy numbers of a synonymous codon for the same amino acid, and $n$ means the number of the interesting gene. The $C$ value ranges from 0 to 1.0. The $C$ value less than 0.3 for a codon position represents low tRNA abundance, and the $C$ value more than 0.7 for a codon position represents high tRNA abundance.

2.3. Estimation of the Relationship between the Synonymous Codon Usage Bias and the Secondary Structure of the nspla. Based on the alignment between the amino acid sequences of the PRRSV (PDB: 3IFU) and the 191 nspl $\alpha$ genes involved in this study, we can locate the different folding units in the target protein. We devised the formula for the $P$ value based on the previous research which analyzed the relationship between the codon usage bias and the structure of the target protein [25]. Consider

$$
\begin{gathered}
P=\ln \frac{f_{\text {obs }}}{f_{\text {exp }}}, \\
f_{\text {obs }}=\frac{N_{(i, \text { sec }-k)}}{N_{(k)}}, \\
f_{\text {exp }}=\frac{\sum N_{(i, \text { sec }-j)}}{N_{\text {total }}},
\end{gathered}
$$

where $N_{(i, \text { sec- } k)}$ represents the amount of a specific synonymous codon for the corresponding amino acid in a specific folding unit (the $\alpha$-helix, the $\beta$-strand, or the coil) of protein; sec- $k$ represents the corresponding amino acid in a specific secondary unit; $N_{(k)}$ represents the amount of the amino acid in the corresponding folding unit. In addition, $\sum N_{(i, \text { sec- } j)}$ represents the total number of amino acids in a specific 
folding unit; sec- $j$ contains the three kinds of folding unit, namely, $\alpha$-helix, $\beta$-strand, and the coil; $N_{\text {total }}$ represents the total number of codons in the target genes. When the $P$ value is more than zero, the corresponding synonymous codon (i) owns a potential to be selected in a specific folding unit. When the $P$ value is less than zero, the synonymous codon (i) has no tendency to be chosen in a specific folding unit. Furthermore, we defined that when the $P$ value is more than 0.1 , the synonymous codon has a strong ability to exist in the specific folding unit; on the contrary, when the $P$ value is less than -0.1 , the synonymous codon has a strong tendency to avoid the specific folding unit.

2.4. Calculation of the Relative Abundance of Codons with Context. With the purpose to estimate the synonymous codons playing an important role in the formation of the specific folding units, codons having a significant tendency to exist in the specific folding unit of the PRRSV $n s p l \alpha$ were analyzed by the formula for the relative abundance of codons with context. Berg and Silva [32] defined that the context $N_{1}$ represents the first nucleotide after the target codon. Following this notation, we defined that the context ${ }_{1} N$ represents the last nucleotide before the target codon. We devised a formula calculating $R$ value for the context $N_{1}(x y z \sim n)$ and the context ${ }_{1} N(n \sim x y z)$ depending on the formula previously reported $[20,34]$. Consider

$$
\begin{aligned}
& R(x y z \sim n)=\frac{F(x y z \sim n)}{F(x y z) F(n)}, \\
& R(n \sim x y z)=\frac{F(n \sim x y z)}{F(x y z) F(n)},
\end{aligned}
$$

where $F(x y z)$ is the frequency of the codon $x y z$ and $F(n)$ is the frequency of nucleotide $n$ in the $N_{1}$ or ${ }_{1} N$ context. $F(x y z \sim n)$ and $F(n \sim x y z)$ are the frequency of a codon with the $n$ context. It is noted that $x, y, z$, and $n$ are the nucleotides $(a, u, g$, or $c)$ and the codon is composed of $x y z$. Here and elsewhere the tilde character $(\sim)$ separates codons (italic) or oligonucleotides (nonunderlined) from their mononucleotide context.

2.5. Calculation of the Relative Abundance of Mononucleotide and Dinucleotides in the nspl $\alpha$ Gene. To investigate whether the $N_{1}$ and ${ }_{1} N$ contexts are shaped by randomness or not, we calculated the frequencies of each nucleotide $F(n)$ and dinucleotide $F(x y)$, where $n, x, y$, and $z$ are each one of the four nucleotides $(a, u, c$, and $g)$. Then we calculated the relative abundances ( $r$ value) of the mononucleotide and dinucleotides with a single nucleotide context: $r(n \sim x)=$ $F(n \sim x) /[F(n) F(x)]$, for mononucleotide $x$ with context $n$; $r(x y \sim n)=F(x y \sim n) /[F(x y) F(n)]$, for dinucleotide $x y$ with context $n$.

2.6. Statistic Analysis. One-way analysis of variance, namely, one-way ANOVA, is a technique used to compare means of two or more samples. In this study, the ANOVA test is applied for identifying whether the overall tRNA abundance of positions of a specific folding unit is different from other specific folding units or not. In addition, the ANOVA test is also employed to estimate whether the frequencies of codon usage in a specific folding unit are different from other specific folding units or not. This statistic analysis is carried out by the software SPSS 11.5.

\section{Results}

3.1. The Overall tRNA Abundance for Each Codon Position of the nspl $\alpha$ Gene. Based on the $C$ values, the tRNA abundance for each codon position along the PRRSV nspl $\alpha$ gene was mapped. The translation speed for the synthesis of the nspl $\alpha$ is not stable in the pigs (Figure 1). The codon positions with the $C$ values much less than 0.30 have a tendency to cluster in $n s p 1 \alpha$ gene, including the positions 4-6, 8-10, 22-25, 27-30, $32-34,38-40,42-47,50-53,55-58,68-70,77-79,83-85,110-$ $112,119-122,126-128,139-141,157-160$, and 171-173. However, the codon positions with the $C$ values much greater than 0.70 have few chances to cluster in $n s p 1 \alpha$ gene which is translated in the pigs. Due to most codon positions with $C$ values much less than 0.70 existing in the target gene, these positions within the $n s p l \alpha$ might reduce the translation rate of this protein when the $n s p l \alpha$ was scanned by the ribosomes in pig cells. It is noted that there are no significant differences $(P>$ 0.05) of the overall tRNA abundance for the codon positions in the regions of the three specific folding units of the nspl $\alpha$. This result suggests that the fluctuation of the overall tRNA abundance pairing to each codon position along this $n s p l \alpha$ might not regulate the formation of the specific folding units but decrease the scanning speed of ribosomes in the pig cells.

3.2. The Relationship between the Synonymous Codon Usage Bias and the Structure of the nspla. Based on the $P$ values for the synonymous codons which are involved in the formation of the specific folding units in the nspl $\alpha$, we found the link between SCUD and the specific folding unit $(P=2.75 \times$ $\left.10^{-11}\right)$. In detail, the synonymous codons have a strong propensity toward shaping the $\alpha$-helix unit, including AUC for Ile, GUA for Val, AGC for Ser, AAG for Lys, and AUG for Met (Table 1). Turning to the effects of SCUB on shaping the $\beta$-strand unit, there are UUA for Leu, AUA for Ile, GUG for Val, UCA and AGU for Ser, ACA for Thr, UAC for Tyr, CGC for Arg, and two synonymous codons for His (Table 1). It is interesting that there are no codons which have a strong tendency to exist in the coil of the nspl $\alpha$ (Table 1). As for the codons which have a strong tendency $(P$ value $>1.0)$ to exist in the nspl $\alpha$, all of them strongly tend to exist only in the $\alpha$ helix or the $\beta$-strand of this protein.

3.3. The Relative Abundance of the Codon with $N_{1}$ Context in the nspla Gene. As for the codons which have a strong tendency to exist in the specific folding unit of the nspl $\alpha$, their $R$ values, the relative abundance of codons with $N_{1}$ contexts, were calculated from the 191 nspl $\alpha$ genes (Table 2). The data show that the occurrence of the codon with $N_{1}$ context or ${ }_{1} N$ context is not random, and many codons with $N_{1}$ context or ${ }_{1} N$ context have a strong tendency to 


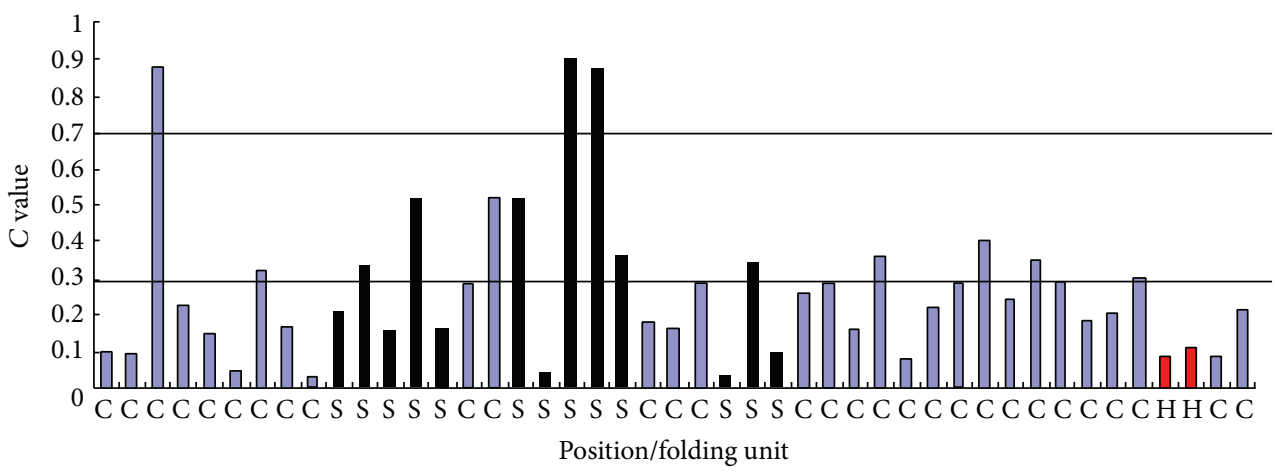

(a)

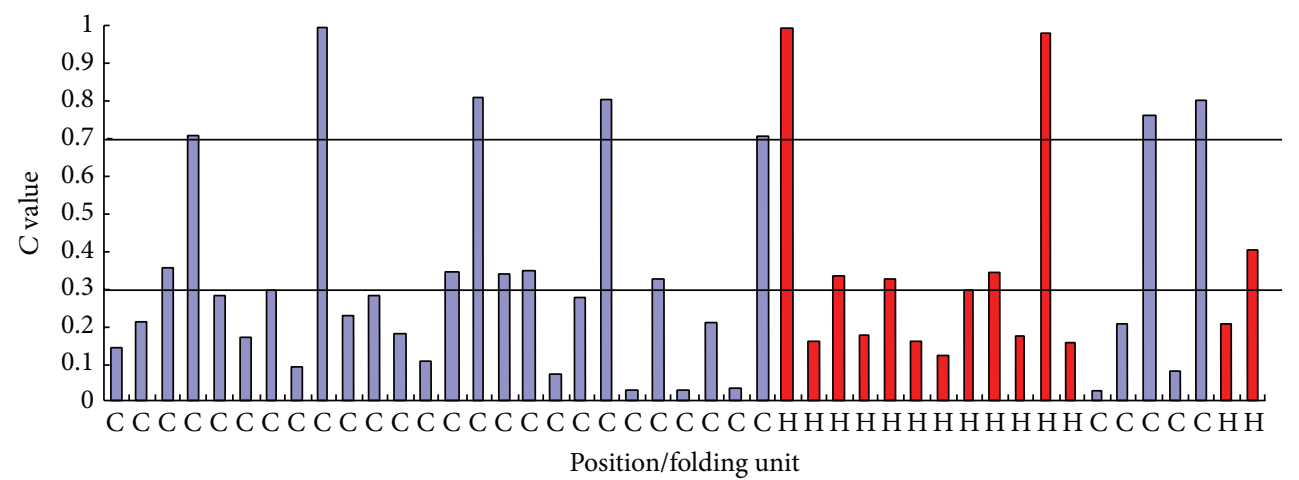

(b)

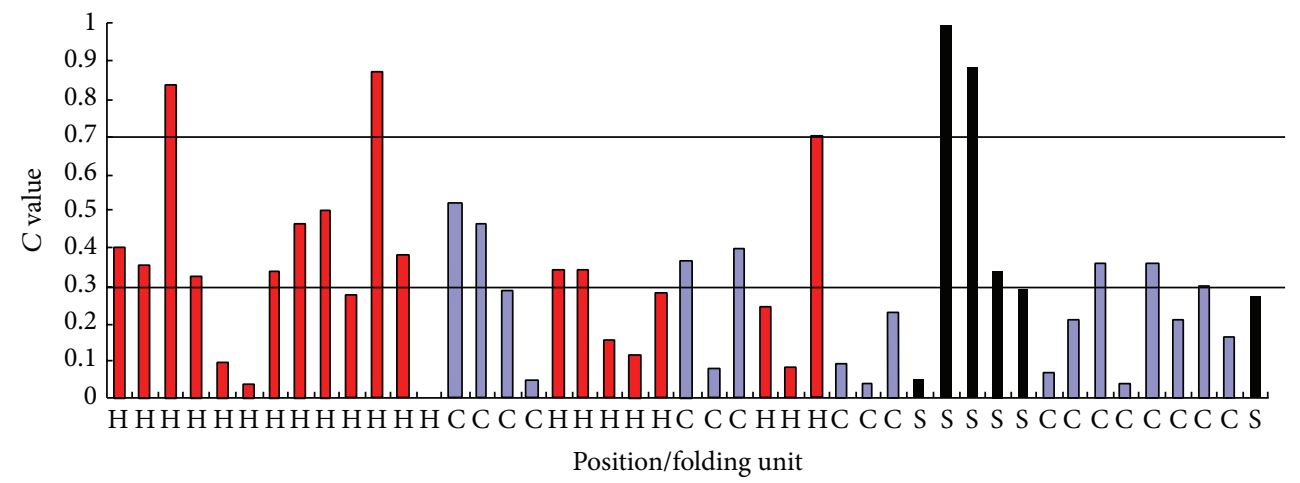

(c)

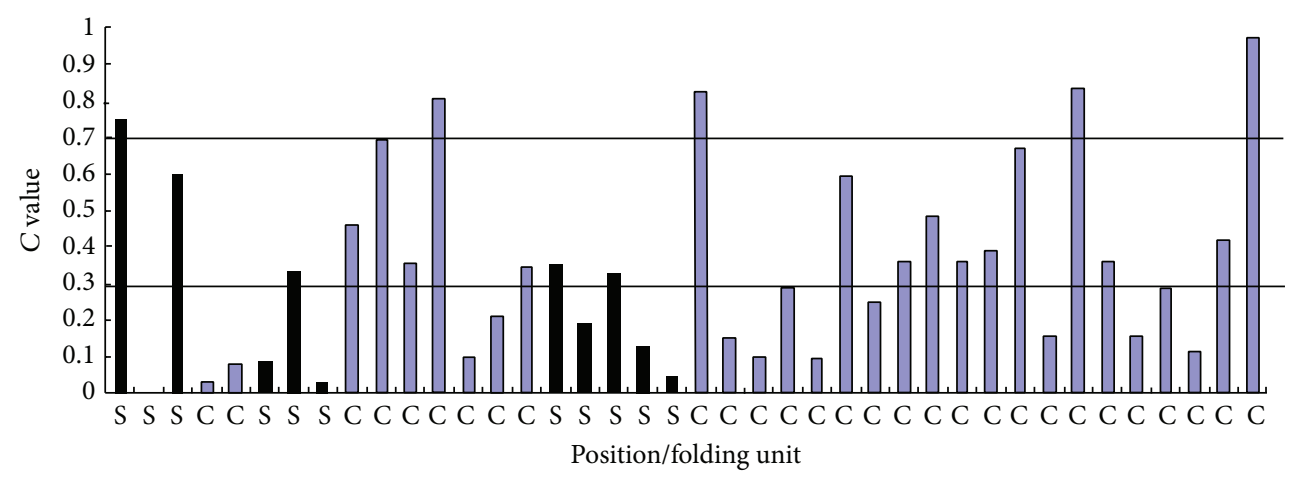

(d)

FIGURE 1: The overall tRNA abundance for each codon position of the PRRSV nspl $\alpha$ gene. The black bar corresponds to the $\beta$-strand region in the $n s p 1 \alpha$; the blue bar corresponds to the coil region in the $n s p 1 \alpha$; the red bar corresponds to helix region in the $n s p 1 \alpha$. (a) The codon positions range from the first position to the 45th position of the $n s p 1 \alpha$. (b) The codon positions range from the 46th position to the 90th position of the $n s p l \alpha$. (c) The codon positions range from the 91th position of the $n s p 1 \alpha$. (d) The codon positions range from the 136 th to the 175 th position of the $n s p 1 \alpha$. 
TABLE 1: The relationship between the synonymous codon usage and the formation of the specific secondary structure unit.

\begin{tabular}{|c|c|c|c|c|}
\hline Amino acid & Codon & ${ }^{\mathrm{a}} P$ value & ${ }^{\mathrm{b}} P$ value & ${ }^{\mathrm{c}} P$ value \\
\hline Phe & UUU & 0.40 & 0.07 & -0.21 \\
\hline Phe & UUC & -0.92 & -0.40 & 0.26 \\
\hline Leu & UUA & -1.07 & 1.47 & -1.22 \\
\hline Leu & UUG & -0.16 & -0.53 & 0.15 \\
\hline Leu & CUU & 0.68 & d- & -0.06 \\
\hline Leu & CUC & -5.53 & -5.32 & 0.48 \\
\hline Leu & CUA & 0.17 & -1.37 & 0.13 \\
\hline Leu & CUG & 0.00 & -4.15 & 0.24 \\
\hline Ile & AUU & 0.99 & 0.92 & -5.46 \\
\hline Ile & AUC & 1.50 & -1.17 & ${ }^{\mathrm{d}}-$ \\
\hline Ile & AUA & 0.69 & 1.12 & -2.46 \\
\hline Val & GUU & 0.58 & 0.28 & -0.45 \\
\hline Val & GUC & 0.32 & 0.20 & -0.21 \\
\hline Val & GUA & 1.27 & 0.02 & -2.17 \\
\hline Val & GUG & -0.52 & 1.21 & -0.73 \\
\hline Ser & UCU & 0.76 & d- & -0.12 \\
\hline Ser & UCC & -4.45 & -3.14 & 0.47 \\
\hline Ser & UCA & d- & 1.76 & d- \\
\hline Ser & UCG & ${ }^{d}-$ & d- & d- \\
\hline Ser & $\mathrm{AGU}$ & -4.79 & 1.35 & -0.61 \\
\hline Ser & AGC & 1.24 & -0.25 & -1.53 \\
\hline Pro & $\mathrm{CCU}$ & -0.48 & -2.90 & 0.33 \\
\hline Pro & CCC & -2.85 & -0.28 & 0.33 \\
\hline Pro & CCA & -0.32 & -4.40 & 0.31 \\
\hline Pro & CCG & -0.23 & -2.69 & 0.28 \\
\hline Thr & $\mathrm{ACU}$ & -0.08 & 0.58 & -0.21 \\
\hline Thr & ACC & -0.57 & 0.53 & -0.05 \\
\hline Thr & ACA & 0.58 & 1.28 & -5.24 \\
\hline Thr & ACG & -4.40 & ${ }^{\mathrm{d}}-$ & 0.48 \\
\hline Ala & GCU & 0.55 & -2.56 & 0.00 \\
\hline Ala & GCC & -0.07 & 0.10 & -0.01 \\
\hline Ala & GCA & 0.78 & 0.16 & -0.61 \\
\hline Ala & GCG & 0.76 & 1.15 & -4.18 \\
\hline Tyr & UAU & 0.95 & -1.60 & -0.39 \\
\hline Tyr & UAC & 0.21 & 1.37 & -2.22 \\
\hline His & CAU & -4.21 & 1.75 & -4.18 \\
\hline His & $\mathrm{CAC}$ & d- & 1.75 & -3.81 \\
\hline Gln & CAA & 0.62 & -0.82 & -0.15 \\
\hline Gln & CAG & -2.74 & 0.63 & 0.07 \\
\hline Asn & $\mathrm{AAU}$ & -4.47 & -0.58 & 0.38 \\
\hline Asn & AAC & d_- & 0.18 & 0.25 \\
\hline Lys & AAA & -0.90 & ${ }^{\mathrm{d}}-$ & 0.39 \\
\hline Lys & AAG & 1.18 & ${ }^{\mathrm{d}}-$ & -0.69 \\
\hline Asp & GAU & d- & -3.17 & 0.48 \\
\hline Asp & GAC & d- & ${ }^{\mathrm{d}}-$ & 0.48 \\
\hline Glu & GAA & 0.93 & d- & -0.28 \\
\hline Glu & GAG & -1.15 & -5.28 & 0.41 \\
\hline Cys & UGU & d- & -4.75 & 0.48 \\
\hline Cys & UGC & -5.41 & 0.04 & 0.28 \\
\hline Arg & CGU & -1.82 & 0.28 & 0.18 \\
\hline
\end{tabular}

TABLE 1: Continued.

\begin{tabular}{lcccc}
\hline Amino acid & Codon & ${ }^{\mathrm{a}} P$ value & ${ }^{\mathrm{b}} P$ value & ${ }^{\mathrm{c}} P$ value \\
\hline Arg & CGC & ${ }^{\mathrm{d}}-$ & $\mathbf{1 . 5 2}$ & -1.03 \\
Arg & CGA & 0.83 & -2.13 & -0.22 \\
Arg & CGG & -0.04 & 0.16 & -0.04 \\
Arg & AGA & $\mathbf{1 . 3 7}$ & -4.30 & -1.32 \\
Arg & AGG & d - & 0.76 & 0.03 \\
Gly & GGU & 0.52 & d - & 0.04 \\
Gly & GGC & -0.34 & -4.61 & 0.32 \\
Gly & GGA & -4.76 & -4.55 & 0.48 \\
Gly & GGG & d - & -4.62 & 0.48 \\
Met & AUG & $\mathbf{1 . 0 1}$ & -0.35 & -0.72 \\
Trp & UGG & 0.45 & 0.66 & -0.61 \\
\hline
\end{tabular}

${ }^{a}$ represents $\alpha$-helix.

${ }^{\mathrm{b}}$ represents $\beta$-strand.

${ }^{c}$ represents The coil.

${ }^{d}$ represents The corresponding codon is not selected in the specific secondary structure unit.

Italic indicates that the corresponding codon has a weak bias to be selected in a specific secondary structure unit.

Bold indicates that the corresponding codon has a tendency to be selected in a specific secondary structure unit.

exist in the specific folding units of the nspl $\alpha$. Based on the data of SCUB in the specific folding units (Table 1), the corresponding codon with $N_{1}$ context was found to have a trend to exist in the specific folding unit of the nspl $\alpha$. In detail, the codons with $N_{1}$ context or ${ }_{1} N$ context (GUA A, AGC $\sim$ A, AAG C , AGA C , A AUA, U AGC, U AAG, C AAG, G AGA, and $U \sim A U G$ ) have an obvious trend to exist in the helix unit of the nspl $\alpha$. Some codons with $N_{1}$ context or ${ }_{1} N$ context have a strong tendency to exist in the $\beta$-strand of the nspl $\alpha$, including UUA A, AUA G, GUG U, UCA C, AGU G, ACA C, UAC U, UAC $\sim \mathrm{C}, \mathrm{CAU} \sim \mathrm{G}, \mathrm{CAC} \sim \mathrm{G}$, CGC $\sim$ U, G UUA, U AUA, U GUG, G GUG, U UCA, C

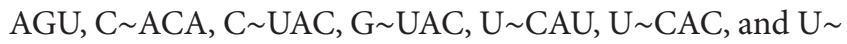
CGC.

In order to identify the roles of nucleotide compositions (dinucleotide with $N_{1}$ context and mononucleotide with $N_{1}$ context) in shaping the codon with $N_{1}$ context or ${ }_{1} N$ context, the $R$ values for these interesting codons with $N_{1}$ context or ${ }_{1} N$ context which have a strong tendency to exist in the helix or the $\beta$-strand were compared with the $r$ values for the dinucleotide/mononucleotide with $N_{1}$ context (Tables 3 and 4 ). The $R$ value for the target codon with $N_{1}$ context is higher than the corresponding dinucleotide/mononucleotide with $N_{1}$ context or ${ }_{1} N$ context. For example, as for GUA which tends to exist in the helix of the nspl $\alpha$ gene, GUA A has a tendency to exist in the helix unit, because the $R$ value (1.4751) of GUA A for the helix unit is higher than the $R$ value for GUA $\sim$ A for the $\beta$-strand and the coil (Table 2) and higher than the $r$ value for $\mathrm{UA} \sim \mathrm{A}$ and the $r$ value for $\mathrm{A} \sim \mathrm{A}$ (Tables 3 and 4). As for UUA which tends to exist in the $\beta$-strand of this gene, UUA A has a tendency to exist in the strand unit, because the $R$ value (4.9268) for UUA A is higher than the $R$ values for UUA A of the helix and the coil and higher than the $r$ values for $\mathrm{UA} \sim \mathrm{A}$ and $\mathrm{A} \sim \mathrm{A}$ (Tables 3 and 4). As for AGC which tends to exist in the helix of this gene, $\mathrm{U} \sim \mathrm{AGC}$ has 
TABLe 2: Relative abundance of codons with $N_{1}$ context or ${ }_{1} N$ context in the PRRSV nspl $\alpha$ gene.

\begin{tabular}{|c|c|c|c|c|c|c|c|}
\hline Codon-context $(x y z-n)$ & $R$ value $^{1}$ & $R$ value $^{2}$ & $R$ value $^{3}$ & Codon-context $(x y z-n)$ & $R$ value $^{1}$ & $R$ value $^{2}$ & $R$ value $^{3}$ \\
\hline UUA $\sim A$ & 0.0000 & 4.9268 & 0.3345 & $\mathrm{~A} \sim \mathrm{UUA}$ & 0.0000 & 0.0401 & 3.6799 \\
\hline UUA U & 0.2911 & 0.0000 & 0.0000 & U UUA & 0.1456 & 0.0617 & 0.2945 \\
\hline UUA C & 2.8120 & 0.0000 & 0.0000 & C $\sim$ UUA & 2.9124 & 0.0000 & 0.0000 \\
\hline UUA G & 0.0000 & 0.0000 & 3.7713 & G UUA & 0.0000 & 3.7019 & 0.0000 \\
\hline $\mathrm{AUC} \sim \mathrm{A}$ & 0.0000 & 0.0000 & 0.0000 & $\mathrm{~A} \sim \mathrm{AUC}$ & 0.0000 & 0.0000 & 2.4430 \\
\hline $\mathrm{AUC} \sim \mathrm{U}$ & 0.0000 & 0.0000 & 3.1392 & $\mathrm{U} \sim \mathrm{AUC}$ & 0.0000 & 0.2233 & 0.0116 \\
\hline $\mathrm{AUC} \sim \mathrm{C}$ & 0.0000 & 0.0000 & 0.0000 & $\mathrm{C} \sim \mathrm{AUC}$ & 0.0000 & 3.4849 & 0.0439 \\
\hline $\mathrm{AUC} \sim \mathrm{G}$ & 0.0000 & 3.7945 & 0.4601 & $\mathrm{G} \sim \mathrm{AUC}$ & 0.0000 & 0.0000 & 1.5563 \\
\hline AUA $\sim \mathrm{A}$ & 0.0000 & 0.0000 & 0.0000 & $\mathrm{~A} \sim \mathrm{AUA}$ & 0.0000 & 0.0000 & 0.0000 \\
\hline $\mathrm{AUA} \sim \mathrm{U}$ & 0.0000 & 0.0000 & 0.0000 & $\mathrm{U} \sim \mathrm{AUA}$ & 4.3672 & 3.4158 & 2.2091 \\
\hline $\mathrm{AUA} \sim \mathrm{C}$ & 3.0128 & 0.0000 & 0.5557 & $\mathrm{C} \sim \mathrm{AUA}$ & 0.0000 & 0.3703 & 0.0000 \\
\hline $\mathrm{AUA} \sim \mathrm{G}$ & 0.0000 & 3.7945 & 3.5998 & $\mathrm{G} \sim \mathrm{AUA}$ & 0.0000 & 0.0000 & 1.5428 \\
\hline GUA $\sim A$ & 1.4751 & 0.0000 & 0.0934 & $\mathrm{~A} \sim \mathrm{GUA}$ & 2.9502 & 3.2845 & 0.0000 \\
\hline $\mathrm{GUA} \sim \mathrm{U}$ & 1.0918 & 3.7954 & 0.0822 & U GUA & 0.0000 & 0.0000 & 0.0000 \\
\hline GUA C & 0.7532 & 0.0000 & 4.2386 & $\mathrm{C} \sim \mathrm{GUA}$ & 0.7532 & 1.2342 & 0.0000 \\
\hline $\mathrm{GUA} \sim \mathrm{G}$ & 0.9274 & 0.0000 & 0.0000 & G GUA & 0.9274 & 0.0000 & 4.1141 \\
\hline $\mathrm{GUG} \sim \mathrm{A}$ & 0.0510 & 0.0000 & 0.0000 & $\mathrm{~A} \sim \mathrm{GUG}$ & 1.4283 & 0.0000 & 0.3526 \\
\hline $\mathrm{GUG} \sim \mathrm{U}$ & 0.2014 & 2.7198 & 0.0000 & $\mathrm{U} \sim \mathrm{GUG}$ & 0.0629 & 1.8132 & 0.0239 \\
\hline $\mathrm{GUG} \sim \mathrm{C}$ & 1.4413 & 0.1874 & 4.4454 & $\mathrm{C} \sim \mathrm{GUG}$ & 0.0174 & 0.4872 & 0.0000 \\
\hline $\mathrm{GUG} \sim \mathrm{G}$ & 1.7318 & 0.8833 & 0.0000 & $\mathrm{G} \sim \mathrm{GUG}$ & 2.7367 & 1.4824 & 3.7249 \\
\hline UCA A & 0.0000 & 0.0000 & 0.0000 & $\mathrm{~A} \sim \mathrm{UCA}$ & 0.0000 & 0.0000 & 0.0000 \\
\hline $\mathrm{UCA} \sim \mathrm{U}$ & 0.0000 & 0.0000 & 0.0000 & $\mathrm{U} \sim \mathrm{UCA}$ & 0.0000 & 3.7954 & 0.0000 \\
\hline $\mathrm{UCA} \sim \mathrm{C}$ & 0.0000 & 3.7027 & 0.0000 & $\mathrm{C} \sim \mathrm{UCA}$ & 0.0000 & 0.0000 & 0.0000 \\
\hline $\mathrm{UCA} \sim \mathrm{G}$ & 0.0000 & 0.0000 & 0.0000 & $\mathrm{G} \sim \mathrm{UCA}$ & 0.0000 & 0.0000 & 0.0000 \\
\hline $\mathrm{AGU} \sim \mathrm{A}$ & 0.0000 & 0.0000 & 0.0000 & $\mathrm{~A} \sim \mathrm{AGU}$ & 0.0000 & 0.0000 & 0.0000 \\
\hline $\mathrm{AGU} \sim \mathrm{U}$ & 0.0000 & 0.0000 & 0.0000 & $\mathrm{U} \sim \mathrm{AGU}$ & 2.4694 & 0.0000 & 0.0000 \\
\hline $\mathrm{AGU} \sim \mathrm{C}$ & 0.0473 & 0.0000 & 0.0000 & $\mathrm{C} \sim \mathrm{AGU}$ & 1.2619 & 3.7027 & 4.4454 \\
\hline $\mathrm{AGU} \sim \mathrm{G}$ & 3.6513 & 3.7945 & 4.1141 & $\mathrm{G} \sim \mathrm{AGU}$ & 0.0583 & 0.0000 & 0.0000 \\
\hline $\mathrm{AGC} \sim \mathrm{A}$ & 2.9502 & 0.0000 & 0.0000 & $\mathrm{~A} \sim \mathrm{AGC}$ & 0.0000 & 0.0000 & 0.0000 \\
\hline $\mathrm{AGC} \sim \mathrm{U}$ & 0.0000 & 0.0000 & 0.0000 & $\mathrm{U} \sim \mathrm{AGC}$ & 5.9004 & 0.0000 & 0.0000 \\
\hline $\mathrm{AGC} \sim \mathrm{C}$ & 0.0000 & 0.0000 & 0.0000 & $\mathrm{C} \sim \mathrm{AGC}$ & 0.0000 & 3.7027 & 0.0000 \\
\hline $\mathrm{AGC} \sim \mathrm{G}$ & 1.8548 & 3.7945 & 0.0000 & $\mathrm{G} \sim \mathrm{AGC}$ & 0.0000 & 0.0000 & 0.0000 \\
\hline $\mathrm{ACA} \sim \mathrm{A}$ & 0.0000 & 0.0000 & 0.0000 & $\mathrm{~A} \sim \mathrm{ACA}$ & 0.0000 & 0.0000 & 0.0000 \\
\hline $\mathrm{ACA} \sim \mathrm{U}$ & 0.0000 & 0.0000 & 0.0000 & $\mathrm{U} \sim \mathrm{ACA}$ & 4.3672 & 0.0000 & 3.4431 \\
\hline $\mathrm{ACA} \sim \mathrm{C}$ & 0.0000 & 3.7027 & 0.0383 & $\mathrm{C} \sim \mathrm{ACA}$ & 0.0000 & 3.7027 & 0.1150 \\
\hline $\mathrm{ACA} \sim \mathrm{G}$ & 3.7096 & 0.0000 & 4.0786 & $\mathrm{G} \sim \mathrm{ACA}$ & 0.0000 & 0.0000 & 0.0000 \\
\hline $\mathrm{UAC} \sim \mathrm{A}$ & 5.6595 & 0.0000 & 3.9513 & $\mathrm{~A} \sim \mathrm{UAC}$ & 0.0000 & 0.0502 & 0.0000 \\
\hline $\mathrm{UAC} \sim \mathrm{U}$ & 0.0000 & 1.4455 & 0.0000 & $\mathrm{U} \sim \mathrm{UAC}$ & 1.2478 & 0.8812 & 1.4434 \\
\hline $\mathrm{UAC} \sim \mathrm{C}$ & 0.1230 & 1.4253 & 0.0000 & $\mathrm{C} \sim \mathrm{UAC}$ & 2.1520 & 1.3876 & 2.6300 \\
\hline $\mathrm{UAC} \sim \mathrm{G}$ & 0.0000 & 0.8887 & 0.0646 & $\mathrm{G} \sim \mathrm{UAC}$ & 0.0000 & 1.4529 & 0.0000 \\
\hline $\mathrm{CAU} \sim \mathrm{A}$ & 0.0000 & 0.0000 & 0.0000 & $\mathrm{~A} \sim \mathrm{CAU}$ & 3.9336 & 0.0000 & 0.0000 \\
\hline $\mathrm{CAU} \sim \mathrm{U}$ & 0.0000 & 0.0000 & 0.0000 & $\mathrm{U} \sim \mathrm{CAU}$ & 0.0000 & 3.7043 & 0.0000 \\
\hline $\mathrm{CAU} \sim \mathrm{C}$ & 1.0043 & 0.0000 & 0.0000 & $\mathrm{C} \sim \mathrm{CAU}$ & 0.0000 & 0.0889 & 4.4454 \\
\hline $\mathrm{CAU} \sim \mathrm{G}$ & 2.4730 & 3.7945 & 4.1141 & $\mathrm{G} \sim \mathrm{CAU}$ & 1.2365 & 0.0000 & 0.0000 \\
\hline $\mathrm{CAC} \sim \mathrm{A}$ & 0.0000 & 0.0000 & 0.0000 & $\mathrm{~A} \sim \mathrm{CAC}$ & 0.0000 & 0.0000 & 0.0000 \\
\hline $\mathrm{CAC} \sim \mathrm{U}$ & 0.0000 & 0.2138 & 0.0000 & $\mathrm{U} \sim \mathrm{CAC}$ & 4.3672 & 3.5816 & 0.0000 \\
\hline $\mathrm{CAC} \sim \mathrm{C}$ & 0.0000 & 0.0000 & 0.0000 & $\mathrm{C} \sim \mathrm{CAC}$ & 0.0000 & 0.2086 & 0.0000 \\
\hline $\mathrm{CAC} \sim \mathrm{G}$ & 3.7096 & 3.5807 & 0.0000 & $\mathrm{G} \sim \mathrm{CAC}$ & 0.0000 & 0.0000 & 0.0000 \\
\hline $\mathrm{AAG} \sim \mathrm{A}$ & 0.0000 & 0.0000 & 3.4986 & $\mathrm{~A} \sim \mathrm{AAG}$ & 0.0000 & 0.0000 & 3.3416 \\
\hline
\end{tabular}


TABLe 2: Continued.

\begin{tabular}{|c|c|c|c|c|c|c|c|}
\hline Codon-context $(x y z-n)$ & $R$ value $^{1}$ & $R$ value $^{2}$ & $R$ value $^{3}$ & Codon-context $(x y z-n)$ & $R$ value $^{1}$ & $R$ value $^{2}$ & $R$ value $^{3}$ \\
\hline $\mathrm{AAG} \sim \mathrm{U}$ & 0.0546 & 0.0000 & 0.0000 & $\mathrm{U} \sim \mathrm{AAG}$ & 1.4739 & 0.0000 & 0.0000 \\
\hline $\mathrm{AAG} \sim \mathrm{C}$ & 2.9751 & 0.0000 & 0.0000 & $\mathrm{C} \sim \mathrm{AAG}$ & 1.9960 & 0.0000 & 0.0000 \\
\hline$A A G \sim G$ & 0.0000 & 0.0000 & 0.5286 & $\mathrm{G} \sim \mathrm{AAG}$ & 0.0000 & 0.0000 & 0.6895 \\
\hline $\mathrm{CGC} \sim \mathrm{A}$ & 1.3112 & 0.0000 & 0.0000 & $\mathrm{~A} \sim \mathrm{CGC}$ & 2.8704 & 0.0000 & 0.0000 \\
\hline $\mathrm{CGC} \sim \mathrm{U}$ & 0.1213 & 3.7954 & 0.0000 & $\mathrm{U} \sim \mathrm{CGC}$ & 0.1180 & 2.3721 & 0.0000 \\
\hline $\mathrm{CGC} \sim \mathrm{C}$ & 0.0837 & 0.0000 & 0.0000 & $\mathrm{C} \sim \mathrm{CGC}$ & 1.3843 & 1.3885 & 0.0000 \\
\hline $\mathrm{CGC} \sim \mathrm{G}$ & 2.6791 & 0.0000 & 0.0000 & $\mathrm{G} \sim \mathrm{CGC}$ & 0.1003 & 0.0000 & 0.0000 \\
\hline $\mathrm{AGA} \sim \mathrm{A}$ & 0.0000 & 0.0000 & 1.9453 & $\mathrm{~A} \sim \mathrm{AGA}$ & 0.0831 & 0.0000 & 2.0578 \\
\hline $\mathrm{AGA} \sim \mathrm{U}$ & 0.1230 & 0.0000 & 0.1188 & $\mathrm{U} \sim \mathrm{AGA}$ & 0.6766 & 0.0000 & 0.0099 \\
\hline $\mathrm{AGA} \sim \mathrm{C}$ & 2.8855 & 0.0000 & 0.0249 & $\mathrm{C} \sim \mathrm{AGA}$ & 0.1273 & 0.0000 & 2.1293 \\
\hline$A G A \sim G$ & 0.0522 & 0.0000 & 1.9591 & $\mathrm{G} \sim \mathrm{AGA}$ & 2.9259 & 0.0000 & 0.0230 \\
\hline $\mathrm{AUG} \sim \mathrm{A}$ & 0.0000 & 0.0000 & 2.1721 & $\mathrm{~A} \sim \mathrm{AUG}$ & 0.0000 & 0.0000 & 3.9812 \\
\hline $\mathrm{AUG} \sim \mathrm{U}$ & 0.0000 & 0.0000 & 0.0000 & $\mathrm{U} \sim \mathrm{AUG}$ & 4.1823 & 3.6955 & 0.0000 \\
\hline $\mathrm{AUG} \sim \mathrm{C}$ & 0.0000 & 0.0000 & 0.0000 & $\mathrm{C} \sim \mathrm{AUG}$ & 0.1275 & 0.0974 & 0.0000 \\
\hline $\mathrm{AUG} \sim \mathrm{G}$ & 0.0000 & 3.7945 & 1.8881 & $\mathrm{G} \sim \mathrm{AUG}$ & 0.0000 & 0.0000 & 0.0340 \\
\hline
\end{tabular}

${ }^{1}$ represents The relative abundance of codons with $N_{1}$ context in the helix unit of the PRRSV $n s p 1 \alpha$.

${ }^{2}$ represents The relative abundance of codons with $N_{1}$ context in the $\beta$-strand unit of the PRRSV $n s p l \alpha$.

${ }^{3}$ represents The relative abundance of codons with $N_{1}$ context in the coil unit of the PRRSV $n s p l \alpha$.

a tendency to exist in the helix rather than in the strand or the coil, because the $R$ value (5.9004) for $U \sim A G C$ is higher than the $R$ value of $\mathrm{U} \sim \mathrm{AGC}$ of the strand and the coil and higher than the $r$ values for $\mathrm{U} \sim \mathrm{AG}$ and $\mathrm{U} \sim \mathrm{A}$ (Tables 3 and 4). As for UUA which tends to exist in the strand of this gene, G UUA has a tendency to exist in the strand unit, because the $R$ value (3.7019) for G UUA of the strand unit is higher than the $R$ values for G UUA of the helix and the coil and higher than $r$ values for $\mathrm{G} \sim \mathrm{UU}$ and $\mathrm{G} \sim \mathrm{U}$ (Tables 3 and 4). Based on the standard mentioned above, GUA A, AGC $\sim A, A A G \sim C$, $\mathrm{AGA} \sim \mathrm{C}, \mathrm{A} \sim \mathrm{GUA}, \mathrm{U} \sim \mathrm{AGC}, \mathrm{U} \sim \mathrm{AAG}, \mathrm{C} \sim \mathrm{AAG}, \mathrm{G} \sim \mathrm{AGA}$, and $\mathrm{U} \sim \mathrm{AUG}$ have a strong trend to exist in the helix of PRRSV nspl $\alpha$ gene and $\mathrm{UUA} \sim \mathrm{A}, \mathrm{AUA} \sim \mathrm{G}, \mathrm{GUG} \sim \mathrm{U}, \mathrm{UCA} \sim \mathrm{C}, \mathrm{ACA} \sim$ $\mathrm{C}, \mathrm{UAC} \sim \mathrm{U}, \mathrm{UAC} \sim \mathrm{C}, \mathrm{CAU} \sim \mathrm{G}, \mathrm{CGC} \sim \mathrm{U}, \mathrm{G} \sim \mathrm{UUA}, \mathrm{U} \sim \mathrm{GUG}$, $\mathrm{U} \sim \mathrm{UCA}, \mathrm{C} \sim \mathrm{AGU}, \mathrm{C} \sim \mathrm{ACA}, \mathrm{G} \sim \mathrm{UAC}, \mathrm{U} \sim \mathrm{CAU}$, and $\mathrm{U} \sim \mathrm{CGC}$ have a strong tendency to exist in the $\beta$-strand of the nspl $\alpha$ gene.

\section{Discussion}

In this study, we have mapped the fluctuation of the overall tRNA abundance for each codon position along the PRRSV nspl $\alpha$ gene and estimated the correlation between the synonymous codon usage and different folding units of the nspl $\alpha$. The performance of mapping the fluctuation of the overall tRNA abundance for each codon position along the target gene likely reflects the translation speed of ribosomes scanning caused by the tRNA abundance of the pigs to some degree, since the tRNA abundance plays an important role in the ribosome scanning along the target coding sequence $[35,36]$. The previous report showed that the $\alpha$-helix is preferentially coded by translationally fast mRNA regions while the slow segments often encode $\beta$-strands and coil regions [37]. In the study, no linkage between the fluctuation of the overall tRNA abundance pairing to the codon positions along the nspl $\alpha$ gene and the specific folding units might suggest that the process of translation fine-tunes is not performed by variation of translation speed for each codon position along the nspla. The fine-tuning in vivo protein folding exists in the gene, and this regularity is largely believed to occur in a cotranslational process [38]. However, the PRRSV nspl $\alpha$ derives from the posttranslational processing of the ppla $[10,39]$. The process of the cleavage of the nspl $\alpha$ from the ppla polyprotein of PRRSV performed by the posttranslation might be free from the fluctuation of tRNA abundance pairing to the each codon position along the nspl $\alpha$ gene. As for the ribosomes scanning the nspl $\alpha$ gene, there is no significant link between the fluctuation of the overall tRNA abundance and the specific folding units, and the translation elongation rate of this gene is not high. These results suggest that the low tRNA abundance controls the ribosomal traffic along the translated message to achieve the effective synthesized product of the PRRSV ppla. The low translational elongation at the translation beginning step directs the target gene to generate the corresponding protein effectively [40].

Turning to the role of the synonymous codon usage in the formation of the specific units of the nspl $\alpha$, there is significant relationship between the synonymous codon usage bias and the specific folding units in the target protein. The synonymous codons assist messenger RNA to carry the information of the specific folding units, and a single codon or a contiguous nucleotide region plays roles in shaping the specific folding units $[24,25,41,42]$. As for the PRRSV $n s p 1 \alpha$, there is no synonymous codon which tends to exist in coil unit. However, many synonymous codons exist in the $\alpha$ helix and $\beta$-strands regions of this gene, and no synonymous codon has a strong tendency to be selected by both the $\alpha$-helix and the $\beta$-strands in the PRRSV nspl $\alpha$ simultaneously. These results indicated that SCUB might play roles in shaping this 
TABLE 3: Relative abundance of dinucleotides with $N_{1}$ context or ${ }_{1} N$ context in the PRRSV nspl $\alpha$ gene.

\begin{tabular}{|c|c|c|c|}
\hline $\begin{array}{l}\text { Dinucleotides with } \\
N_{1} \text { context }(x y \sim n)\end{array}$ & $r$ value & $\begin{array}{l}\text { Dinucleotides with } \\
\left.{ }_{1} N \text { context } n \sim x y\right)\end{array}$ & $r$ value \\
\hline $\mathrm{UC} \sim \mathrm{A}$ & 0.6130 & $\mathrm{~A} \sim \mathrm{AU}$ & 1.4456 \\
\hline $\mathrm{UC} \sim \mathrm{U}$ & 1.3115 & $\mathrm{U} \sim \mathrm{AU}$ & 0.8552 \\
\hline $\mathrm{UC} \sim \mathrm{C}$ & 1.2805 & $\mathrm{C} \sim \mathrm{AU}$ & 0.6485 \\
\hline $\mathrm{UC} \sim \mathrm{G}$ & 0.5669 & $\mathrm{G} \sim \mathrm{AU}$ & 1.0047 \\
\hline $\mathrm{UA} \sim \mathrm{A}$ & 0.6177 & $\mathrm{~A} \sim \mathrm{GU}$ & 1.2963 \\
\hline $\mathrm{UA} \sim \mathrm{U}$ & 1.0269 & $\mathrm{U} \sim \mathrm{GU}$ & 1.1651 \\
\hline $\mathrm{UA} \sim \mathrm{C}$ & 1.7402 & $\mathrm{C} \sim \mathrm{GU}$ & 0.5072 \\
\hline $\mathrm{UA} \sim \mathrm{G}$ & 0.4351 & $\mathrm{G} \sim \mathrm{GU}$ & 1.1064 \\
\hline $\mathrm{UG} \sim \mathrm{A}$ & 1.2060 & $\mathrm{~A} \sim \mathrm{UC}$ & 0.5880 \\
\hline $\mathrm{UG} \sim \mathrm{U}$ & 0.8195 & $\mathrm{U} \sim \mathrm{UC}$ & 1.0330 \\
\hline $\mathrm{UG} \sim \mathrm{C}$ & 1.0921 & $\mathrm{C} \sim \mathrm{UC}$ & 1.1230 \\
\hline $\mathrm{UG} \sim \mathrm{G}$ & 0.8019 & $\mathrm{G} \sim \mathrm{UC}$ & 1.0286 \\
\hline $\mathrm{CA} \sim \mathrm{A}$ & 1.8155 & $\mathrm{~A} \sim \mathrm{AG}$ & 1.2415 \\
\hline $\mathrm{CA} \sim \mathrm{U}$ & 0.4556 & $\mathrm{U} \sim \mathrm{AG}$ & 0.2825 \\
\hline $\mathrm{CA} \sim \mathrm{C}$ & 0.9184 & $\mathrm{C} \sim \mathrm{AG}$ & 0.9946 \\
\hline $\mathrm{CA} \sim \mathrm{G}$ & 0.8963 & $\mathrm{G} \sim \mathrm{AG}$ & 1.5135 \\
\hline GU A & 0.3165 & $\mathrm{~A} \sim \mathrm{AC}$ & 1.5521 \\
\hline GU U & 0.9679 & $\mathrm{U} \sim \mathrm{AC}$ & 0.9913 \\
\hline GU C & 0.8485 & $\mathrm{C} \sim \mathrm{AC}$ & 0.8942 \\
\hline $\mathrm{GU} \sim \mathrm{G}$ & 1.5896 & $\mathrm{G} \sim \mathrm{AC}$ & 0.6067 \\
\hline $\mathrm{GC} \sim \mathrm{A}$ & 1.2887 & $\mathrm{~A} \sim \mathrm{UA}$ & 0.6720 \\
\hline $\mathrm{GC} \sim \mathrm{U}$ & 1.0849 & U UA & 0.9776 \\
\hline $\mathrm{GC} \sim \mathrm{C}$ & 1.3411 & $\mathrm{C} \sim \mathrm{UA}$ & 1.6741 \\
\hline $\mathrm{GC} \sim \mathrm{G}$ & 0.3298 & G UA & 0.5155 \\
\hline $\mathrm{CA} \sim \mathrm{A}$ & 1.8155 & $\mathrm{~A} \sim \mathrm{CA}$ & 0.9721 \\
\hline $\mathrm{CA} \sim \mathrm{U}$ & 0.4556 & $\mathrm{U} \sim \mathrm{CA}$ & 0.4819 \\
\hline $\mathrm{CA} \sim \mathrm{C}$ & 0.9184 & $\mathrm{C} \sim \mathrm{CA}$ & 1.3762 \\
\hline $\mathrm{CA} \sim \mathrm{G}$ & 0.8963 & $\mathrm{G} \sim \mathrm{CA}$ & 1.0994 \\
\hline $\mathrm{AC} \sim \mathrm{A}$ & 0.9465 & $\mathrm{~A} \sim \mathrm{AA}$ & 1.1734 \\
\hline $\mathrm{AC} \sim \mathrm{U}$ & 1.2243 & $\mathrm{U} \sim \mathrm{AA}$ & 0.3547 \\
\hline $\mathrm{AC} \sim \mathrm{C}$ & 0.8848 & $\mathrm{C} \sim \mathrm{AA}$ & 1.7821 \\
\hline $\mathrm{AC} \sim \mathrm{G}$ & 0.9524 & $\mathrm{G} \sim \mathrm{AA}$ & 1.4708 \\
\hline $\mathrm{AU} \sim \mathrm{A}$ & 0.5596 & $\mathrm{~A} \sim \mathrm{CG}$ & 1.6312 \\
\hline $\mathrm{AU} \sim \mathrm{U}$ & 0.9124 & $\mathrm{U} \sim \mathrm{CG}$ & 0.7431 \\
\hline $\mathrm{AU} \sim \mathrm{C}$ & 0.6579 & $\mathrm{C} \sim \mathrm{CG}$ & 1.2830 \\
\hline $\mathrm{AU} \sim \mathrm{G}$ & 1.7819 & $\mathrm{G} \sim \mathrm{CG}$ & 0.4693 \\
\hline $\mathrm{AG} \sim \mathrm{A}$ & 1.0440 & $\mathrm{~A} \sim \mathrm{UU}$ & 0.8843 \\
\hline$A G \sim U$ & 1.3708 & $\mathrm{U} \sim \mathrm{UU}$ & 1.5257 \\
\hline $\mathrm{AG} \sim \mathrm{C}$ & 0.7761 & $\mathrm{C} \sim \mathrm{UU}$ & 1.2791 \\
\hline$A G \sim G$ & 0.8164 & $\mathrm{G} \sim \mathrm{UU}$ & 1.2724 \\
\hline $\mathrm{GC} \sim \mathrm{A}$ & 1.2887 & & \\
\hline $\mathrm{GC} \sim \mathrm{U}$ & 1.0849 & & \\
\hline $\mathrm{GC} \sim \mathrm{C}$ & 1.3411 & & \\
\hline $\mathrm{GC} \sim \mathrm{G}$ & 0.3298 & & \\
\hline
\end{tabular}

TABLE 4: Relative abundance of mononucleotide with $N_{1}$ context in PRRSV nspl $\alpha$ gene.

\begin{tabular}{lc}
\hline Mononucleotide with $\mathrm{N}_{1}$ context & $r(x \sim n)$ \\
\hline $\mathrm{A} \sim \mathrm{A}$ & 1.0664 \\
$\mathrm{~A} \sim \mathrm{U}$ & 0.7354 \\
$\mathrm{~A} \sim \mathrm{C}$ & 1.0751 \\
$\mathrm{~A} \sim \mathrm{G}$ & 0.9433 \\
$\mathrm{U} \sim \mathrm{A}$ & 0.6124 \\
$\mathrm{U} \sim \mathrm{U}$ & 0.7588 \\
$\mathrm{U} \sim \mathrm{C}$ & 0.8228 \\
$\mathrm{U} \sim \mathrm{G}$ & 1.4182 \\
$\mathrm{C} \sim \mathrm{A}$ & 1.0468 \\
$\mathrm{C} \sim \mathrm{U}$ & 1.1225 \\
$\mathrm{C} \sim \mathrm{C}$ & 0.8788 \\
$\mathrm{C} \sim \mathrm{G}$ & 0.6277 \\
$\mathrm{G} \sim \mathrm{A}$ & 1.0557 \\
$\mathrm{G} \sim \mathrm{U}$ & 0.9975 \\
$\mathrm{G} \sim \mathrm{C}$ & 0.8930 \\
$\mathrm{G} \sim \mathrm{G}$ & 0.7782 \\
\hline
\end{tabular}

protease with natural properties for the life-cycle of PRRSV. SCUB for formation of the specific folding units of the PRRSV $n s p l \alpha$ is influenced by the natural selection. As an example of the role for natural selection, the expressivity of genes is an important factor in shaping SCUB, both for prokaryotic and for eukaryotic organisms [18, 22, 43, 44]. Although the link between the SCUB and the formation of the specific folding units was reported $[25,35,37,38,45]$, the role of CDCB in formation of specific folding units is not clear. In this study, we found that $\mathrm{CDCB}$ plays a role in the formation of specific folding units in the PRRSV nspl $\alpha$. The synonymous usage bias and $\mathrm{CDCB}$, which play important roles in achieving accuracy and efficiency in protein synthesis, are particular manifestations of coding sequence nonrandomness [23, 46, 47]. Spatial interaction of ribosomal proteins with codonanticodon RNA pairs inside the $\mathrm{A}$ and $\mathrm{P}$ sites of the ribosome could be preferable for particular codons with context [20, 48].

\section{Conflict of Interests}

The authors declare that there is no conflict of interests regarding the publication of this paper.

\section{Authors' Contribution}

Yao-zhong Ding, Ya-nan You, and Dong-jie Sun contributed to the original draft of the paper and approved the final version. Hao-tai Chen, Yong-lu Wang, Hui-yun Chang, Li Pan, Yu-zhen Fang, Zhong-wang Zhang, Peng Zhou, Jianliang Lv, Xinsheng Liu, Jun-jun Shao, Fu-rong Zhao, and Tong Lin downloaded the sequences and analyzed the data. Laszlo Stipkovits, Zygmunt Pejsak, Yong-guang Zhang, and Jie Zhang provided suggestive information to the Discussion 
and revised the paper. All authors read and approved the final version.

\section{Acknowledgments}

This work was supported in part by Grants from International Science and Technology Cooperation Program of China (no. 2012DFG31890) and Gansu Provincial Funds for Distinguished Young Scientists (1111RJDA005). This study was also supported by National Natural Science foundation of China (no. 31172335 and no. 31072143).

\section{References}

[1] J. G. Cho and S. A. Dee, "Porcine reproductive and respiratory syndrome virus," Theriogenology, vol. 66, no. 3, pp. 655-662, 2006.

[2] K.-K. Conzelmann, N. Visser, P. van Woensel, and H.-J. Thiel, "Molecular characterization of porcine reproductive and respiratory syndrome virus, a member of the arterivirus group," Virology, vol. 193, no. 1, pp. 329-339, 1993.

[3] J. J. M. Meulenberg, M. M. Hulst, E. J. De Meijer et al., "Lelystad virus, the causative agent of porcine epidemic abortion and respiratory syndrome (PEARS), is related to LDV and EAV," Virology, vol. 192, no. 1, pp. 62-72, 1993.

[4] R. Allende, T. L. Lewis, Z. Lu et al., "North American and European porcine reproductive and respiratory syndrome viruses differ in non-structural protein coding regions," Journal of General Virology, vol. 80, part 2, pp. 307-315, 1999.

[5] E. M. Bautista, S. M. Goyal, I. J. Yoon, H. S. Joo, and J. E. Collins, "Comparison of porcine alveolar macrophages and CL 2621 for the detection of porcine reproductive and respiratory syndrome (PRRS) virus and anti-PRRS antibody," Journal of Veterinary Diagnostic Investigation, vol. 5, no. 2, pp. 163-165, 1993.

[6] J. E. Collins, D. A. Benfield, W. T. Christianson et al., "Isolation of swine infertility and respiratory syndrome virus (isolate ATCC VR-2332) in North America and experimental reproduction of the disease in gnotobiotic pigs," Journal of Veterinary Diagnostic Investigation, vol. 4, no. 2, pp. 117-126, 1992.

[7] Y. S. Liu, J. H. Zhou, H. T. Chen et al., "Analysis of synonymous codon usage in porcine reproductive and respiratory syndrome virus," Infection, Genetics and Evolution, vol. 10, no. 6, pp. 797$803,2010$.

[8] C. J. Nelsen, M. P. Murtaugh, and K. S. Faaberg, "Porcine reproductive and respiratory syndrome virus comparison: divergent evolution on two continents," Journal of Virology, vol. 73, no. 1, pp. 270-280, 1999.

[9] E. J. Snijder, A. L. M. Wassenaar, L. C. Van Dinten, W. J. M. Spaan, and A. E. Gorbalenya, "The arterrvirus Nsp4 protease is the prototype of a novel group of chymotrypsin-like enzymes, the 3C-like serine proteases," Journal of Biological Chemistry, vol. 271, no. 9, pp. 4864-4871, 1996.

[10] Y. Fang and E. J. Snijder, “The PRRSV replicase: exploring the multifunctionality of an intriguing set of nonstructural proteins," Virus Research, vol. 154, no. 1-2, pp. 61-76, 2010.

[11] D. D. Nedialkova, A. E. Gorbalenya, and E. J. Snijder, "Arterivirus Nsp1 modulates the accumulation of minus-strand templates to control the relative abundance of viral mRNAs," PLOS Pathogens, vol. 6, no. 2, Article ID e1000772, 2010.

[12] J. A. den Boon, K. S. Faaberg, J. J. M. Meulenberg et al., "Processing and evolution of the $\mathrm{N}$-terminal region of the arterivirus replicase ORFla protein: identification of two papainlike cysteine proteases," Journal of Virology, vol. 69, no. 7, pp. 45004505, 1995.

[13] E. J. Snijder, A. L. M. Wassenaar, and W. J. M. Spaan, "The 5 ' end of the equine arteritis virus replicase gene encodes a papainlike cysteine protease," Journal of Virology, vol. 66, no. 12, pp. 70407048, 1992.

[14] T. Dokland, “The structural biology of PRRSV," Virus Research, vol. 154, no. 1-2, pp. 86-97, 2010.

[15] M. V. Kroese, J. C. Zevenhoven-Dobbe, J. N. A. Bos-de Ruijter et al., "The nsp $1 \alpha$ and nsp $1 \beta$ papain-like autoproteinases are essential for porcine reproductive and respiratory syndrome virus RNA synthesis," Journal of General Virology, vol. 89, no. 2, pp. 494-499, 2008.

[16] S. Yuna, X. Fei, G. Yu et al., "Crystal structure of porcine reproductive and respiratory syndrome virus leader protease Nsp1a," Journal of Virology, vol. 83, no. 21, pp. 10931-10940, 2009.

[17] X. Shi, J. Chen, G. Xing et al., "Amino acid at position 176 was essential for porcine reproductive and respiratory syndrome virus (PRRSV) non-structural protein $1 \alpha(\mathrm{nspl} \alpha)$ as an inhibitor to the induction of IFN- $\beta$," Cellular Immunology, vol. 280, no. 2, pp. 125-131, 2012.

[18] I. Bahir, M. Fromer, Y. Prat, and M. Linial, "Viral adaptation to host: a proteome-based analysis of codon usage and amino acid preferences," Molecular Systems Biology, vol. 5, article 311, 2009.

[19] T. F. Clarke IV and P. L. Clark, "Rare codons cluster," PLoS ONE, vol. 3, no. 10, Article ID e3412, 2008.

[20] A. Fedorov, S. Saxonov, and W. Gilbert, "Regularities of contextdependent codon bias in eukaryotic genes," Nucleic Acids Research, vol. 30, no. 5, pp. 1192-1197, 2002.

[21] J. Zhou, Z. Gao, J. Zhang et al., "The analysis of codon bias of foot-and-mouth disease virus and the adaptation of this virus to the hosts," Infection, Genetics and Evolution, vol. 14, no. 1, pp. 105-110, 2013.

[22] J. Zhou, J. Su, H. Chen et al., "Clustering of low usage codons in the translation initiation region of hepatitis C virus," Infection, Genetics and Evolution, vol. 18, pp. 8-12, 2013.

[23] H. Akashi, "Synonymous codon usage in Drosophila melanogaster: natural selection and translational accuracy," Genetics, vol. 136, no. 3, pp. 927-935, 1994.

[24] I. Weygand-Durasevic and M. Ibba, "Cell biology: new roles for codon usage," Science, vol. 329, no. 5998, pp. 1473-1474, 2010.

[25] J. h. Zhou, Y. N. You, H. T. Chen et al., "The effects of the synonymous codon usage and tRNA abundance on protein folding of the 3C protease of foot-and-mouth disease virus," Infection, Genetics and Evolution, vol. 16, pp. 270-274, 2013.

[26] T. Zhou, M. Weems, and C. O. Wilke, "Translationally optimal codons associate with structurally sensitive sites in proteins," Molecular Biology and Evolution, vol. 26, no. 7, pp. 1571-1580, 2009.

[27] Y. Guisez, J. Robbens, E. Remaut, and W. Fiers, "Folding of the MS2 coat protein in Escherichia coli is modulated by translational pauses resulting from mRNA secondary structure and codon usage: a hypothesis," Journal of Theoretical Biology, vol. 162, no. 2, pp. 243-252, 1993.

[28] X. Tao and D. Dafu, "The relationship between synonymous codon usage and protein structure," FEBS Letters, vol. 434, no. 1-2, pp. 93-96, 1998.

[29] M. Gouy, "Codon contexts in enterobacterial and coliphage genes," Molecular Biology and Evolution, vol. 4, no. 4, pp. 426444, 1987. 
[30] S. Karlin and J. Mrázek, "What drives codon choices in human genes?" Journal of Molecular Biology, vol. 262, no. 4, pp. 459$472,1996$.

[31] E. G. Shpaer, "Constraints on codon context in Escherichia coli genes. Their possible role in modulating the efficiency of translation," Journal of Molecular Biology, vol. 188, no. 4, pp. 555-564, 1986.

[32] O. G. Berg and P. J. N. Silva, "Codon bias in Escherichia coli: The influence of codon context on mutation and selection," Nucleic Acids Research, vol. 25, no. 7, pp. 1397-1404, 1997.

[33] J. D. Thompson, D. G. Higgins, and T. J. Gibson, "CLUSTAL W: improving the sensitivity of progressive multiple sequence alignment through sequence weighting, position-specific gap penalties and weight matrix choice," Nucleic Acids Research, vol. 22, no. 22, pp. 4673-4680, 1994.

[34] S. Karlin and C. Burge, "Dinucleotide relative abundance extremes: a genomic signature," Trends in Genetics, vol. 11, no. 7, pp. 283-290, 1995.

[35] J. L. Parmley and M. A. Huynen, "Clustering of codons with rare cognate tRNAs in human genes suggests an extra level of expression regulation," PLoS Genetics, vol. 5, no. 7, Article ID e1000548, 2009.

[36] E. P. C. Rocha, "Codon usage bias from tRNA's point of view: redundancy, specialization, and efficient decoding for translation optimization," Genome Research, vol. 14, no. 11, pp. 2279-2286, 2004.

[37] T. A. Thanaraj and P. Argos, "Protein secondary structural types are differentially coded on messenger RNA," Protein Science, vol. 5, no. 10, pp. 1973-1983, 1996.

[38] A. A. Komar, "A pause for thought along the co-translational folding pathway," Trends in Biochemical Sciences, vol. 34, no. 1, pp. 16-24, 2009.

[39] D. van Aken, J. Zevenhoven-Dobbe, A. E. Gorbalenya, and E. J. Snijder, "Proteolytic maturation of replicase polyprotein ppla by the nsp 4 main proteinase is essential for equine arteritis virus replication and includes internal cleavage of nsp7," Journal of General Virology, vol. 87, no. 12, pp. 3473-3482, 2006.

[40] T. Tuller, A. Carmi, K. Vestsigian et al., "An evolutionarily conserved mechanism for controlling the efficiency of protein translation," Cell, vol. 141, no. 2, pp. 344-354, 2010.

[41] D. B. Carlini, Y. Chen, and W. Stephan, "The relationship between third-codon position nucleotide content, codon bias, mRNA secondary structure and gene expression in the drosophilid alcohol dehydrogenase genes Adh and Adhr," Genetics, vol. 159, no. 2, pp. 623-633, 2001.

[42] R. Saunders and C. M. Deane, "Synonymous codon usage influences the local protein structure observed," Nucleic Acids Research, vol. 38, no. 19, pp. 6719-6728, 2010.

[43] M. D. Ermolaeva, "Synonymous codon usage in bacteria," Current Issues in Molecular Biology, vol. 3, no. 4, pp. 91-97, 2001.

[44] J. B. Plotkin, H. Robins, and A. J. Levine, "Tissue-specific codon usage and the expression of human genes," Proceedings of the National Academy of Sciences of the United States of America, vol. 101, no. 34, pp. 12588-12591, 2004.

[45] G. Zhang and Z. Ignatova, "Generic algorithm to predict the speed of translational elongation: implications for protein biogenesis," PLoS ONE, vol. 4, no. 4, Article ID e5036, 2009.

[46] A. Eyre-Walker, "Synonymous codon bias is related to gene length in Escherichia coli: selection for translational accuracy?" Molecular Biology and Evolution, vol. 13, no. 6, pp. 864-872, 1996.
[47] J. Precup and J. Parker, "Missense misreading of asparagine codons as a function of codon identity and context," The Journal of Biological Chemistry, vol. 262, no. 23, pp. 11351-11355, 1987.

[48] R. Green and H. F. Noller, "Ribosomes and translation," Annual Review of Biochemistry, vol. 66, pp. 679-716, 1997. 

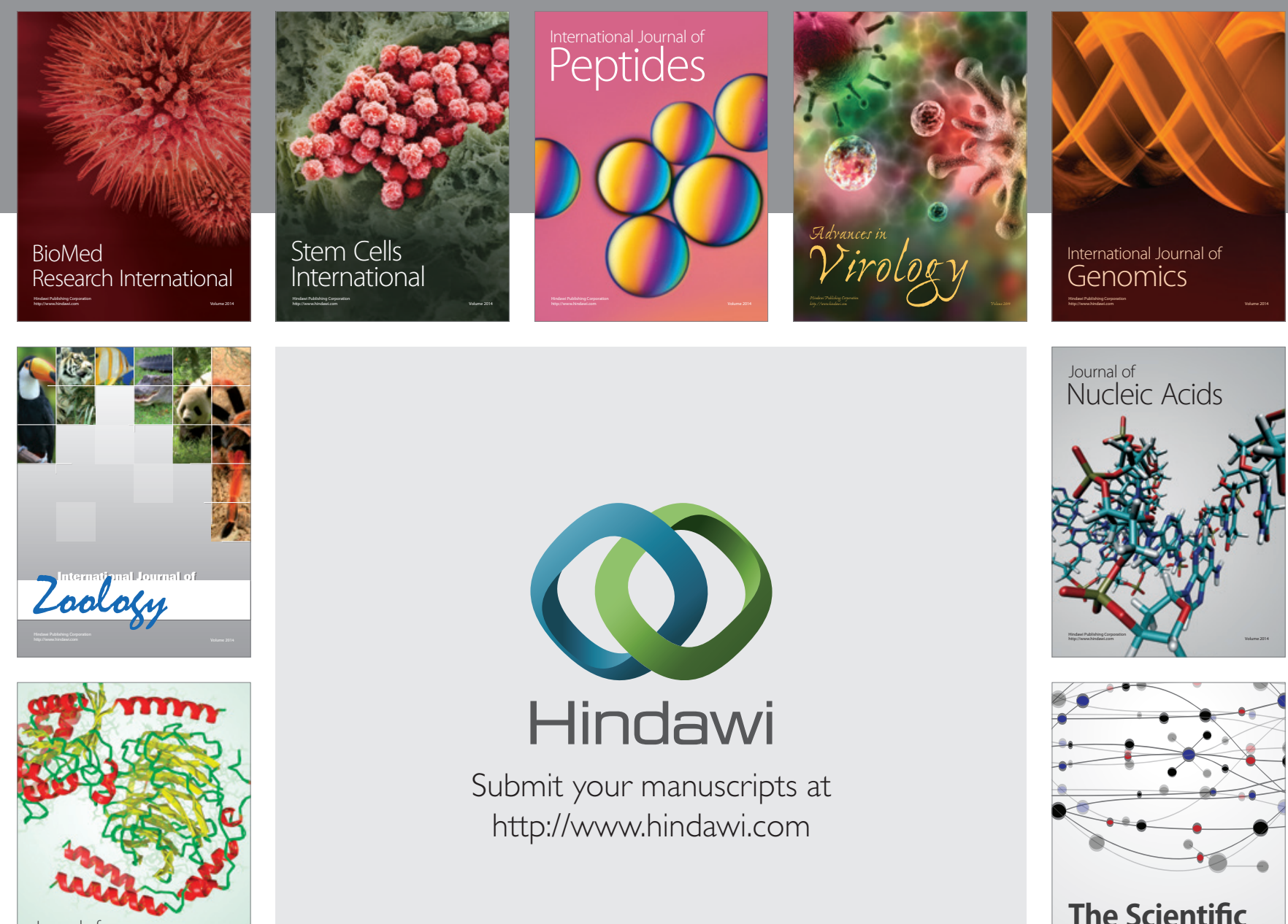

Submit your manuscripts at

http://www.hindawi.com

Journal of
Signal Transduction
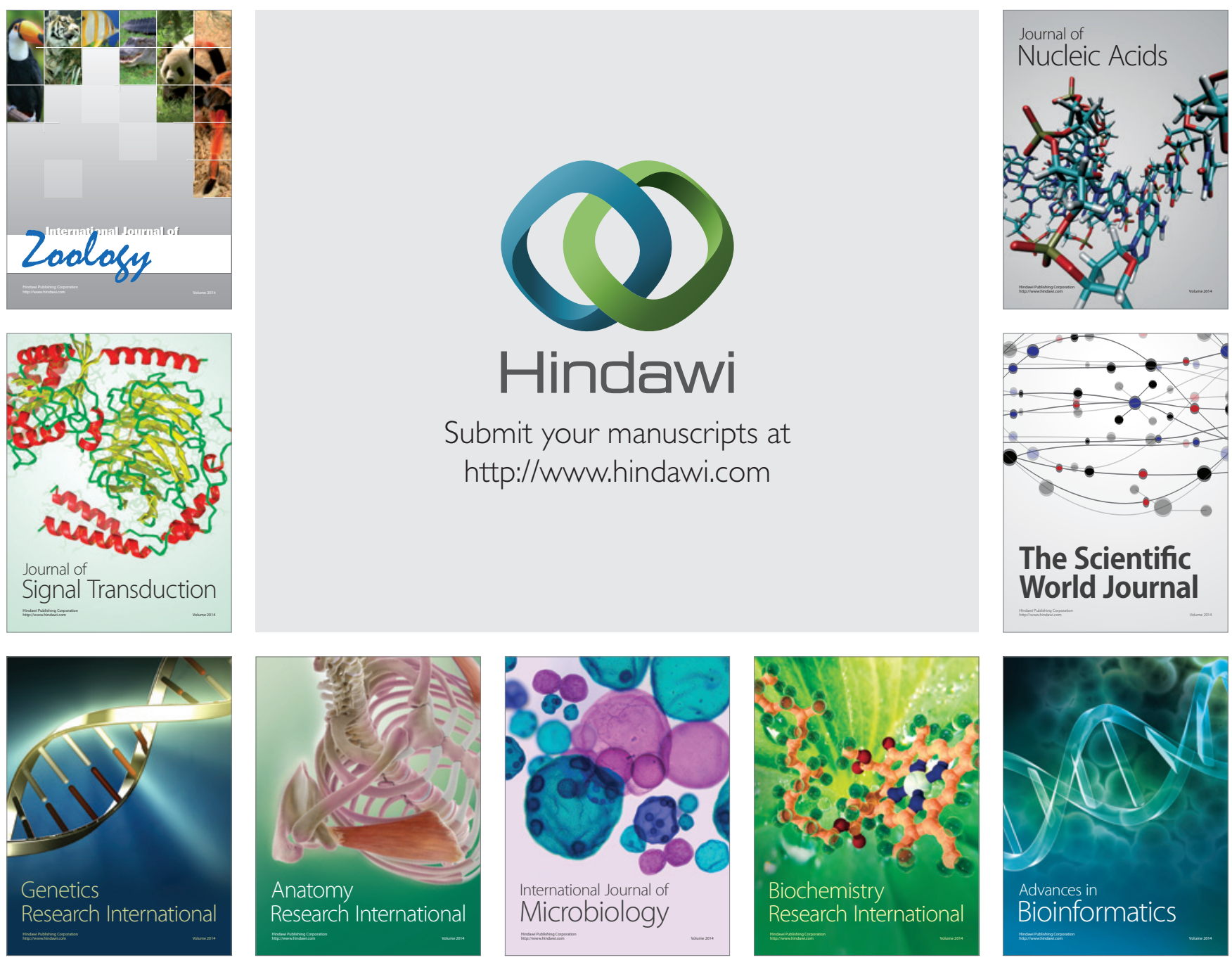

The Scientific World Journal
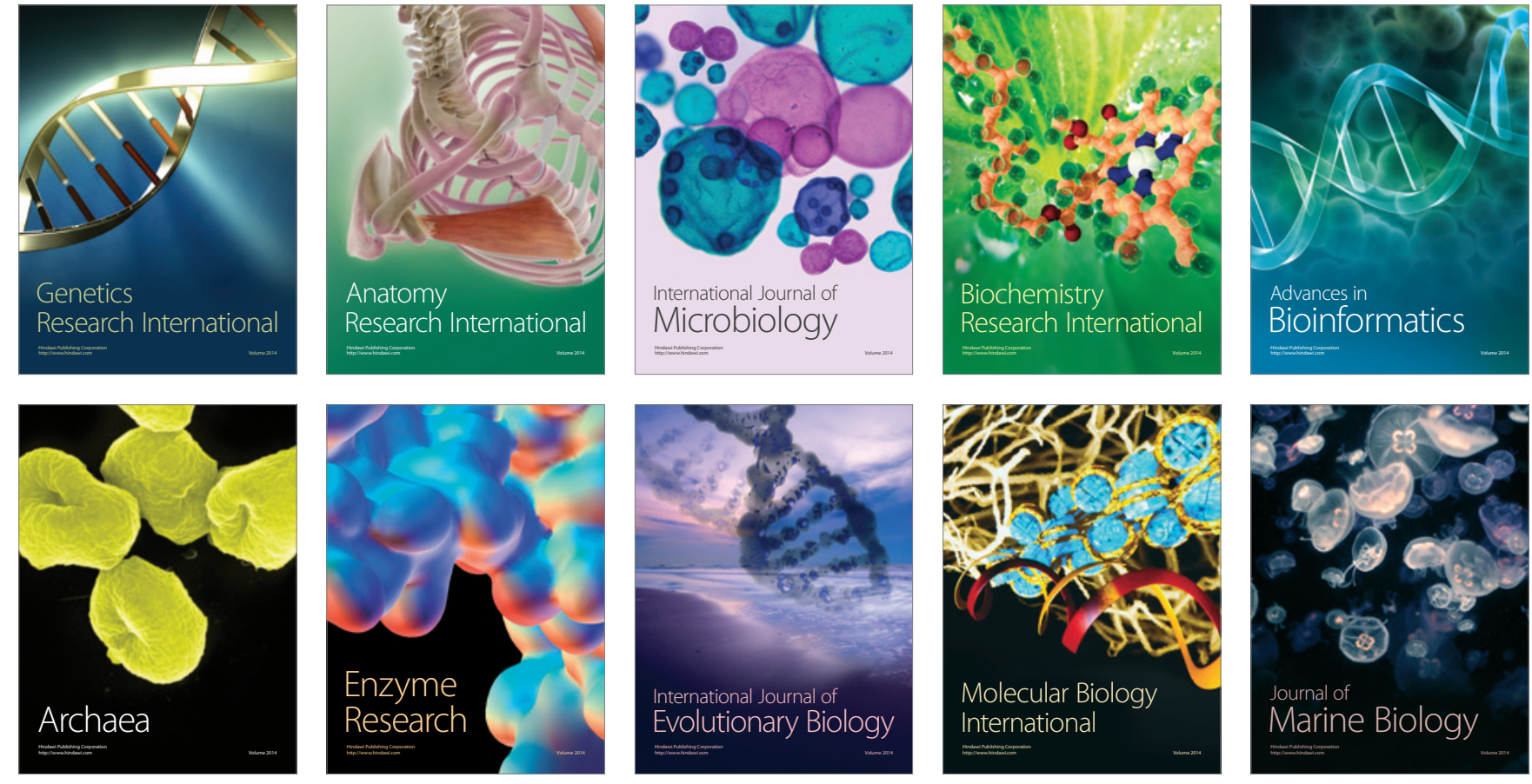